\title{
Qualidade da cama de frango de corte e a alternativa da acidificação como tratamento
}

\author{
Nariane Silva GONÇALVES ${ }^{*}$, Claudia Marie KOMIYAMA², Claudineli Cássia Bueno da ROSA², \\ Juliana de Fátima Pereira de LIMA ${ }^{1}$, Marcela Daiane Gouveia de MORAIS ${ }^{1}$, Fátima Balbino SAVEGNAGO ${ }^{3}$, \\ Carlos MEZZALIRA JÚNIOR ${ }^{3}$, Lidiane STAUB ${ }^{3}$
}

\footnotetext{
1, 4, 5 Programa de Pós-graduação em Zootecnia, Universidade Federal de Mato Grosso, Sinop, Mato Grosso, Brasil.

${ }^{2}$ Faculdade de Ciências Agrárias da Universidade Federal da Grande Dourados, Dourados, Mato Grosso do Sul, Brasil.

${ }^{3}$ Instituto de Ciências Agrárias e Ambientais, Universidade Federal de Mato Grosso, Sinop, Mato Grosso, Brasil.

*E-mail: narianesilvagoncalves@gmail.com
}

Recebido em julho/2018; Aceito em agosto/2019.

\begin{abstract}
RESUMO: Uma prática comum na avicultura em muitos países, incluindo o Brasil é a reutilização da cama de frango por vários lotes, representa uma forma de diminuir custos com a aquisição de nova cama, aumentar a quantidade de nutrientes na cama para ser utilizada como biofertilizante na agricultura e estabilizar ou diminuir o impacto ambiental com a produção de cama por ave produzida. Com isso, algumas alternativas podem ser estudadas para tratamento da cama de frango reutilizadas, a fim de diminuir os impactos causados as aves, ambiente e seres humanos. Diante disso, os condicionadores químicos vêm sendo utilizados como método de tratamento da cama, pois quando aplicados sobre a mesma agem reduzindo o $\mathrm{pH}$ e consequentemente produzindo um ambiente desfavorável para os microorganismos produtores de amônia. Portanto objetivou-se apresentar uma abordagem dos principais fatores que afetam a qualidade da cama de frango, bem como as alternativas para tratamento com ênfase no uso acidificantes aplicados diretamente na cama. O método da acidificação da cama vem se mostrando eficaz para redução do $\mathrm{pH}$ e consequentemente para diminuição da volatilização da amônia, desencadeando assim outros fatores qualitativos como a redução da carga microbiológica, uma vez que estas estão ligadas diretamente com o pH da cama.
\end{abstract}

Palavras-chave: amônia; pH; Salmonella; tratamento químico.

\section{Quality of chicken litter and the alternative of acidification as treatment}

\begin{abstract}
A common practice in poultry farming in many countries, including Brazil is the reuse of the chicken litter by various lots, represents a way to reduce costs by acquiring a new chicken litter, increasing the amount of nutrients in the chicken litter to be used as a biofertilizer in agriculture and stabilizing or reducing the environmental impact with the production of bedding per chicken produced. With this, some alternatives can be studied for the treatment of reused poultry litter, in order to reduce the impacts caused by chicken, environment and humans. Therefore, the chemical treatment have been used as a method of treatment of the chicken litter, because when applied on the same act reducing the $\mathrm{pH}$ and consequently producing an unfavorable environment for the microorganisms producing ammonia. Therefore, it was aimed to present an approach of the main factors that affect the quality of the poultry litter, as well as the alternatives for treatment with emphasis on the use of acidifying agents applied directly to the poultry litter. The method of acidification of the bed has been shown to be effective in reducing $\mathrm{pH}$ and consequently reducing the volatilization of ammonia, thus triggering other qualitative factors such as the reduction of the microbiological load, since these are directly linked to the $\mathrm{pH}$ of the chicken litter.
\end{abstract}

Keywords: ammonia; $\mathrm{pH}$; Salmonella; chemical treatment.

\section{INTRODUÇÃO}

A cama de frango tem a função de absorver a umidade, fornecer isolamento térmico e proporcionar uma superfície macia para as aves, o que evita a formação de calo no peito e de lesões no coxim plantar, no joelho e no peito (HERNANDES; CAZETTA, 2001). A mesma varia em sua composição, e as suas características físicas divergem entre os aviários e em diferentes regiões (DAO; ZHANG, 2007). E essa variação pode ser atribuída a quantidade e o tipo de material da cama, número de lotes e densidade de frangos produzidos na cama, frequência de manejo que se realiza, temperatura ambiente e estações do ano, como por exemplo a alta ou baixa pluviosidade.
É uma prática comum na avicultura criar vários lotes de aves sobre uma mesma cama. A prática da reutilização da cama de frango é uma forma de igualar ou diminuir os custos com a aquisição de nova cama, aumentar a quantidade de nutrientes para ser utilizada como biofertilizante na agricultura e estabilizar ou diminuir o impacto ambiental com a produção de cama por ave produzida (FUKAYAMA, 2009).

No entanto, essa reutilização pode levar a altos níveis de amônia no interior dos galpões, de 60 a 100 ppm, um valor considerado acima do recomendado, que deve ser inferior a 20 ppm (GLOBALGAP, 2007). O pH da cama desempenha papel importante na volatilização da amônia. $\mathrm{O}$ acúmulo de amônia e material fecal aumenta o $\mathrm{pH}$ da cama, que varia tipicamente 
de 7 a 8,5 (REHBEGER, 2002). A liberação de amônia é menor quando o pH da cama está abaixo de 7,0, mas é substancial quando está acima de 8,0, sendo que a decomposição do ácido úrico é mais favorecida em condições de $\mathrm{pH}$ alcalino (TERZICH, 1997).

Dessa forma, algumas alternativas para o tratamento da cama estão sendo avaliadas no intuito de reduzir o $\mathrm{pH}$ da cama de frango e melhorar a qualidade física química e microbiológica propiciando maior conforto às aves, favorecendo seu desempenho zootécnico e sanitário.

Sendo assim, o tratamento com condicionadores químicos é apontado como uma solução rápida e econômica para reduzir a volatilização da amônia e amenizar alguns problemas como o aumento na incidência de doenças respiratórias nas aves e no ser humano.

Diante disso, objetivou-se com essa revisão de literatura abordar os principais fatores que afetam a qualidade da cama de frango, bem como as alternativas para o seu tratamento, com ênfase no uso acidificantes aplicados diretamente na cama.

\section{PANORAMA DA AVICULTURA DE CORTE}

O segmento avícola brasileiro teve um acentuado desenvolvimento nos últimos anos, entre 2005 e 2015 a produção mundial aumentou pouco mais de $40 \%$ colocando o país como segundo maior produtor (AVISITE, 2016), e primeiro maior exportador no ranking mundial, tendo um consumo per capita médio de 42,78 kg em 2014, sendo essa quantidade de $2,30 \%$ a mais em relação à média estimada de 2013 (ABPA, 2015).

Atualmente, mais de 150 mercados são importadores da carne de frango do Brasil. Entre produtores, funcionários de empresas e profissionais vinculados direta e indiretamente ao setor, a avicultura reúne mais de 3,5 milhões de trabalhadores. Cerca de 350 mil deles trabalham diretamente nas plantas frigoríficas. No campo, são mais de 130 mil famílias proprietárias de pequenos aviários, que produzem em um sistema totalmente integrado com as agroindústrias exportadoras (ABPA, 2015).

\section{IMPORTÂNCIA DA CAMA NA AVICULTURA DE CORTE}

$\mathrm{Na}$ avicultura industrial, a ave permanece praticamente toda sua vida sobre a cama, tendo apenas dois pequenos períodos sem contato com essa, que é o tempo que vai da eclosão no incubatório até a chegada ao aviário e o período do carregamento no aviário até a chegada à plataforma do abatedouro. Neste contexto, a cama é fundamental neste segmento e deve proporcionar o máximo de condições de conforto e bem estar às aves para garantir toda a expressão do seu potencial genético (DAÍ PRÁ et al., 2014).

A cama de frango apresenta grande impacto na qualidade e na produtividade dos frangos de corte, sendo um item de importância fundamental para o manejo de aviários em sistemas de produção avícola. Apresenta como função absorver a umidade, diluir uratos e excretas, fornecer isolamento térmico e proporcionar uma superfície macia para as aves, o que evita a formação de calo no peito e de lesões no coxim plantar e no joelho (HERNANDES; CAZETTA, 2001).

Vários materiais são utilizados como cama, sendo esses, a maravalha, casca de amendoim, casca de arroz, casca de café, capim seco, sabugo de milho picado, entre vários outros, e seu uso e disponibilidade variam de acordo com cada região e estação do ano (GRIMES, 2004). Em estudo realizado por Santos (2000), foram utilizados diferentes tipos de materiais como cama de frango, como o cepilho de madeira, casca de arroz, casca de café e sabugo de milho na qual se avaliou o desempenho de frangos de corte criados sobre esses tipos de cama. Os autores não encontraram efeito significativo nas variáveis ganho de peso, consumo de ração e conversão alimentar entre os diferentes tipos de camas testados, demonstrando o uso efetivo de materiais alternativos como cama para frangos.

Porém, a escolha do material a ser utilizado como cama é fundamental, pois a ave irá passar todo o ciclo produtivo na mesma, devendo ser levada em consideração algumas características de qualidade para este fim, como baixa formação de cascão, boa capacidade de absorver a umidade das excretas, manutenção do volume inicial e boa taxa de fermentação após a utilização. Outro aspecto de importância é a disponibilidade (dependendo de cada região) e o custo de aquisição da matéria prima a ser utilizada como cama.

Uma prática bastante comum na avicultura de muitos países, incluindo o Brasil, é a reutilização de cama de frango em mais de um lote de aves. A prática da reutilização da cama de frango é uma forma de igualar ou diminuir os custos com a aquisição de nova cama, aumentar a quantidade de nutrientes na cama para ser utilizada como biofertilizante na agricultura e estabilizar ou diminuir o impacto ambiental com a produção de cama por ave produzida (FUKAYAMA, 2009).

Segundo Souza (2005), os produtores brasileiros utilizam, em média, a mesma cama para produzir cinco lotes de aves. Após a criação do lote, a cama é composta, além do substrato inicial, de excretas, restos de rações, penas, pele e insetos. Essa constituição resulta, em média, em 14\% de proteína bruta, 16\% de fibra bruta, $13 \%$ de matéria mineral e $0,41 \%$ de extrato etéreo (FIORENTIN, 2005). Desta forma, a cama tem uma condição especial para o desenvolvimento bacteriano com índices adequados de $\mathrm{pH}$, entre 8 e 9 em camas reutilizadas, e atividade de água entre 0,90 e 0,92 (DAÍ PRÁ et al., 2010). Aliado a isso tudo, a temperatura da cama varia em condições normais de 20 a $32^{\circ} \mathrm{C}$ no aviário dependendo da semana de criação, completando um habitat ótimo para o crescimento e multiplicação de bactérias (ÁVILA et al., 1992).

Dessa forma, a cama de frango deve ser manejada adequadamente para prevenir a proliferação de insetos e para controlar o nível de umidade e amônia, a produção de poeira e a exposição a agentes transmissores de doenças nos aviários (HERNANDES et al., 2002). Segundo Fiorentin (2005), o manejo correto da cama é essencial para a saúde e o desempenho das aves e também para a qualidade final da carcaça, influenciando os lucros dos produtores e dos integradores.

Neste sentido, tem-se verificado a necessidade de maiores estudos relacionados com o manejo adequado, principalmente com a qualidade da cama (SANTOS, 2000). De acordo com Silva (2011), existem vários métodos de manejo de cama voltados à inativação e controle de patógenos entre lotes, sendo que no Brasil os mais frequentemente utilizados são a fermentação em leira, adição de condicionador químico na cama e a fermentação plana, que consiste na cobertura da cama com lona em toda a extensão do aviário.

Outro método bastante utilizado e indispensável como manejo da cama é o revolvimento, na qual segundo Lana (2000), a cama de frango precisa ser revolvida diariamente, principalmente nos primeiros dias e em horários de 
temperaturas mais amenas, para evitar a formação de placas como decorrência da umidade provocada pelo acúmulo de excretas e água derramada dos bebedouros. Porém, quando ocorrer problemas de cama molhada, esta deve ser removida e substituída por cama nova, além do que, a formação de placas favorece ao aumento da incidência de calosidade nos pés das aves (pododermatites).

\section{QUALIDADE DA CAMA}

A cama é o principal subproduto do ciclo de produção de aves e é composta, além de material absorvente, da excreta, restos de ração, penas, insetos e secreções (SANTOS et al., 2012). Dessa forma deve ser manejada adequadamente a fim de manter sua qualidade e consequentemente o bom desempenho das aves.

Vários fatores podem afetar a qualidade da cama aviária, tais como tipo ou composição da ração, natureza e quantidade do material de cobertura do piso do galpão, período de permanência das aves sobre a cama, número de aves por área, condições e período de estocagem, temperatura ambiental e utilização de equipamentos de resfriamento, como nebulizadores e ventiladores, entre outros. Dentre as características físicas e químicas que podem afetar a qualidade da cama de frango tem-se principalmente, temperatura ambiental, umidade, pH e amônia.

\subsection{Umidade da cama}

O nível de umidade da cama é um fator crítico no manejo dos galpões, já que influencia a incidência e a severidade das lesões na carcaça das aves (QIU; GUO, 2010) e controla a volatilização da amônia, pois o aumento da umidade promove uma maior liberação de amônia nos galpões de frangos de corte (HERNANDES et al., 2002). Segundo Oliveira et al. (2004), a umidade da cama está relacionada a fatores como tipo de dieta, consumo de água, temperatura ambiental, densidade de alojamento, ventilação e, principalmente, tipo de bebedouro usado.

De acordo com Daí Prá; Roll (2014), os níveis de umidade na cama devem situar-se entre 20 e $35 \%$. Cama com índice de umidade abaixo de $20 \%$ resulta em aumento da concentração de poeira no interior da instalação, irritando o sistema respiratório das aves, predispondo ao surgimento de infecções. Por outro lado, o excesso de umidade da cama, ou seja, índice acima de $35 \%$, podem causar problemas de saúde e/ou bemestar nas aves, aumento da incidência de lesões no peito, queimaduras na pele, pododermatites, condenações e perda da qualidade nas carcaças.

Os mesmos autores ainda afirmam que a cama com alta umidade pode também contribuir para o aumento dos níveis de amônia emitidos dentro dos galpões. A umidade associada com o processo de maturação da cama permite a proliferação de alguns tipos de fungos e bactérias desnitrificantes que desdobram o ácido úrico fecal através da enzima uricase, fazendo com que haja uma desestabilização do meio gerando vários subprodutos prejudiciais para as aves, sendo que o principal deles é a amônia que é uma substância com $\mathrm{pH}$ bastante elevado, alcalinizando o substrato que é de origem vegetal e inicialmente ácido.

\subsection{Temperatura}

Segundo Oliveira et al. (2006), entre os diversos fatores que influenciam a produção de frangos de corte, os fatores ambientais, como a temperatura assumem relevante importância no processo de criação das aves. As instalações devem assegurar a manutenção da homeotermia das aves, para manter o conforto térmico animal e garantir o bem-estar na produção (NASCIMENTO, 2011). Nesse sentido, a cama de frango está diretamente relacionada com a temperatura ambiental, na qual de acordo com Daí Prá; Roll (2014), em condições normais, a temperatura da cama deve situar-se próxima da temperatura do ambiente interno do aviário, para dar condições de bem-estar e não interferir negativamente no desempenho das aves.

A temperatura no ambiente do aviário varia em condições normais de 20 a $32^{\circ} \mathrm{C}$ (ÁVILA et al., 1992) dependendo da semana de criação. Boshouwersm (1996) observou que a temperatura da cama de uma criação de frangos de corte a partir do $19^{\circ}$ dia de idade foi $7^{\circ} \mathrm{C}$ superior em relação a temperatura ambiente. Segundo este mesmo autor, este aumento na temperatura da cama pode contribuir, juntamente com o calor gerado pelas aves e pelo fluxo de calor entre a instalação e o ambiente externo, para um aumento na temperatura interna dos galpões e como uma carga adicional de calor para as aves.

Diante disso, o ambiente precisa receber atenção necessária para diminuir este impacto relacionado à qualidade da cama, como instalações adequadas, cortinas e equipamentos, dentre esses, os ventiladores e nebulizadores que são itens importantes no manejo de ventilação e ambiência, essencial para manutenção da qualidade da cama de aviário, principalmente nos períodos críticos de alta temperatura no verão (ÁVILA et al., 2008).

\section{$4.3 \mathrm{pH}$}

$\mathrm{O}$ conceito de $\mathrm{pH}$ está relacionado com a concentração de hidrogênio presente em um determinado meio. $\mathrm{O}$ pH é uma característica de todas as substâncias, determinado pela concentração de íons de hidrogênio $(\mathrm{H}+)$. Os valores variam de zero a 14, sendo que valores de zero e abaixo de 7 são considerados ácidos, valores em torno de 7 são neutros e valores acima de 7 são denominados básicos ou alcalinos (SILVA et al., 2010). Para Jeffrey (2001), o pH da cama pode variar desde o levemente ácido $(\mathrm{pH} 6,0)$ até o francamente alcalino ( $\mathrm{pH} 9,0)$.

$\mathrm{O}$ pH é um indicador de elétrons dissociáveis e pode ser manipulado para cima ou para baixo dificultando, dessa forma, a multiplicação das bactérias patogênicas (TIQUIA et al., 2000). Sendo que o $\mathrm{pH}$ da cama é levemente ácida quando essa é nova, mas a partir da incorporação das excretas e o posterior desdobramento do ácido úrico em amônia começa gradativamente a ocorrer à alcalinização da mesma (DAÍ PRÁ; ROLL, 2014).

$\mathrm{O} \mathrm{pH}$ da cama desempenha papel importante na volatilização da amônia. $\mathrm{O}$ acúmulo de amônia e material fecal aumenta o pH da cama, que varia tipicamente de 7 a 8,5 (REHBEGER, 2002). A liberação de amônia é menor quando o pH da cama está abaixo de 7,0, mas é substancial quando está acima de 8,0, sendo que a decomposição do ácido úrico é mais favorecida em condições de $\mathrm{pH}$ alcalino (TERZICH, 1997). Daí Prá et al. (2010) afirmam que a cama tem uma condição especial para o desenvolvimento bacteriano com índices adequados de $\mathrm{pH}$ entre 8 e 9 em camas reutilizadas. Essa variação de aumento do $\mathrm{pH}$ favorece a maior capacidade de multiplicação da maioria das bactérias de interesse na produção de frangos de corte, incluindo as bactérias patogênicas. 
O manejo da cama de frango se faz necessario para a diminuição do $\mathrm{pH}$ e consequentemente para a redução dos fatores negativos causados pelos microorganismos atuantes na cama, uma vez que também reduz a volatilização da amônia (FIORENTIN, 2005).

\subsection{Amônia}

A amônia é um gás incolor e causa irritação das mucosas (Gonzáles; Saldanha, 2001), é um composto nitrogenado formado por um átomo de nitrogênio e três de hidrogênio $\left(\mathrm{NH}_{3}\right)$. Sua origem está na decomposição microbiana do ácido úrico presente nas excretas das aves (RANDALL et al., 2000).

Oliveira; Godoi (2010) afirmam que a amônia é um subproduto desse processo de decomposição microbiana, e quando liberada para o ambiente em altas concentrações pode causar doenças respiratórias, diminuindo conversão alimentar e consequentemente a taxa de crescimento das aves alojadas.

A indústria avícola, com intuito de manter a competitividade do setor vem produzindo frangos em altas densidades de alojamento, o que acarreta em alterações no conforto térmico das aves e aumenta o aporte de excretas na cama, gerando maior potencial de produção de gases oriundos da fermentação desse material (FREITAS et al., 2011).

$\mathrm{O}$ íon amônio $\left(\mathrm{NH}_{4}+\right)$ é a forma dominante de nitrogênio na excreta de aves, o qual é convertido em amônia $\left(\mathrm{NH}_{3}\right)$ com a elevação do $\mathrm{pH}$ e sob condições de umidade. Este fato torna a amônia o gás mais nocivo produzido em galpões de frangos (CARLILE, 1984).

A liberação de amônia é menor em pH abaixo de 7, entretanto, é maior quando está acima de 8 (TERZICH, 1997). A cama com alta umidade pode também contribuir para o aumento dos níveis de amônia, pois em condições de umidade excessiva, a cama pode produzir amônia a partir do metabolismo microbiano sobre os resíduos fecais (SANTOS et al., 2012). Adicionalmente, a umidade associada com o processo de maturação da cama permite a proliferação de alguns tipos de fungos e bactérias desnitrificantes que desdobram o ácido úrico fecal através da enzima uricase (DAÍ PRÁ; ROLL, 2014) produzindo a amônia.

Quando a quantidade de amônia inalada é superior a 60 ppm, a ave fica predisposta a doenças respiratórias, aumentando os riscos de infecções secundárias às vacinações. Quando o nível de amônia no ambiente atinge 100 ppm, há redução da taxa e profundidade da respiração, prejudicando os processos fisiológicos de trocas gasosas. Esses níveis altos de amônia (60 a $100 \mathrm{ppm}$ ) podem ser observados no início da criação em aviários com a reutilização da cama (GONZÁLES; SALDANHA, 2001).

Para humanos, em particular, a exposição a concentrações muito altas de amônia pode causar danos sérios nos pulmões ou ser letal (FERREIRA, 2010). Segundo Zanatta (2007), o olfato humano não detecta a presença de amônia em níveis abaixo de $20 \mathrm{ppm}$. Além disso, os humanos perdem a sua sensibilidade olfativa depois de longas ou repetidas exposições ao mesmo odor. Dessa forma, os trabalhadores são afetados muito antes que o problema seja percebido ou identificado, o mesmo autor ainda afirma que de 100 a 200 ppm, a amônia induz sonolência, salivação e inapetência.

No Brasil, não existem limites legais para a exposição de aves à amônia, entretanto exportadores de carne de frango adotam o limite de exposição constante máximo de 20 ppm, quando as concentrações de amônia em sistema de criação intensivo fechado pode apresentar, na última semana de produção, valores de até 50 ppm (MIRAGLIOTTA, 2000; JONES et al., 2005) ou até superiores dependendo da condição de renovação do ar interno desses aviários.

\subsection{Microbiologia da cama}

A microbiota da cama é extremamente diversificada em função do contínuo aporte de excretas durante o ciclo de criação, além da incorporação de fungos e bactérias derivados do ambiente (JORGE et al., 1995).

De acordo com Resende (2010), as características microbiológicas da cama de frango podem estar associadas, ao mesmo tempo, a um material potencialmente contaminante, como também de grande utilidade ao se considerar o ativo metabolismo microbiano que se instala através da quantidade de matéria orgânica que a cama recebe ao longo do ciclo de criação das aves. A maioria das bactérias patogênicas que prejudicam os frangos também são potencialmente patogênicas para o homem (LAVERGNE et al., 2006). Além disso, todas as bactérias de origem alimentar são mesófilas e crescem em temperatura ambiente $\left(10\right.$ a $\left.50{ }^{\circ} \mathrm{C}\right)$ (FRANCO, 1996). Portanto, uma alta contagem de bactérias mesófilas na cama pode indicar alto grau de contaminação.

Um exemplo importante de mesófilo é o gênero Staphylococcus, que é composto por uma variedade de espécies associadas a infecções em seres humanos e animais. Dentre essas destacam-se as espécies $S$. aureus, S. epidermidis, S. saprophyticus e $S$. haemolyticus (TRABULSI et al., 1999).

A presença de bactérias mesófilas em grande número indica matéria-prima muito contaminada, limpeza e desinfecção de superfícies inadequadas, higiene insuficiente na produção e condições inapropriadas de temperatura (BERALDO et al., 2013).

Outro grupo de bactérias patogênicas que são encontradas na cama de frango são Enterobactérias, dentre estas estão algumas bactérias causadoras de zoonoses, como o caso da Salmonella e Escherichia coli, em geral, são as que geram preocupações devido a possíveis problemas causados por essas bactérias no lote de frangos e consequentemente na saúde do consumidor (FIORENTIN, 2005).

As bactérias da família Enterobacteriaceae estão distribuídas mundialmente. Essas são encontradas no solo, na água, frutas, vegetais, grãos, flores, árvores e em animais, desde insetos ao homem (BERGEY; HOLT et al., 1994). A sua maioria habita os intestinos do homem e animais, seja como membros da microbiota normal ou como agentes infecciosos (TRABULSI; CAMPOS, 2002).

Dentre as bactérias, as do gênero Salmonella sp. apresenta maior importância na avicultura por representarem risco de contaminação alimentar em seres humanos, uma vez que geralmente as pessoas são infectadas pelo consumo ou contato com alimentos contaminados (DAÍ PRÁ et al., 2009). As salmoneloses aviárias podem ter como agente causal, dentre outros, a Salmonella Enteritidis e Salmonella Typhimurium, as quais são classificadas em patologia aviária como salmonelas paratíficas, ou seja, provocam doenças agudas ou crônicas em aves e muitos outros animais (KWAK et al., 2005).

\section{TRATAMENTO DA CAMA DE FRANGO}

$\mathrm{O}$ tratamento da cama de frango é fundamental quando se faz reutilizações consecutivas por vários lotes, sendo necessário para diminuir os impactos causados na sua qualidade por lotes anteriores. Segundo Silva (2011), vários métodos são utilizados como tratamento de cama de aviário, 
no Brasil os mais frequentemente utilizados são a fermentação em leira (formar leiras com o substrato utilizado como cama, na tentativa de promover a fermentação), adição da cal (tratamento químico) e a fermentação plana (cobertura da cama como lona em toda a extensão do aviário).

Além disso, Roll et al. (2011) relatam que várias substâncias têm sido adicionadas na cama de frango, no intuito de melhorar sua qualidade microbiológica. Tais substâncias podem alterar também as propriedades bromatológicas da cama de frango, possibilitando oportunidades de estudos nesta área.

Diante disso, o tratamento com condicionadores químicos é apontado como uma solução rápida e econômica para reduzir a volatilização da amônia e amenizar alguns problemas como o aumento na incidência de doenças respiratórias nas aves e no ser humano, a desclassificação de carcaça devido à lesões na pele e também a redução do teor de nitrogênio na cama, o que altera seu valor como fertilizante (OLIVEIRA et al., 2003).

Adicionar elementos químicos à cama causa alterações no $\mathrm{pH}$ e propicia um meio desfavorável ao crescimento de microorganismos patogênicos para a cadeia avícola. O manejo correto da cama nos galpões avícolas é área chave na produção, porque afeta a saúde das aves, o desempenho e a lucratividade (LUCCA et al., 2012). A redução do pH, além de diminuir a carga bacteriana da cama, reduz a volatilização da amônia, melhorando as condições ambientais do aviário, pois a volatilização da amônia ocorre em $\mathrm{pH} 7,0$ ou superior (IVANOV, 2001)

Recentemente, vários condicionadores acidificantes têm sido desenvolvidos como tratamento de cama, os quais reduzem significativamente os níveis de amônia nos galpões. Esses produtos agem tanto por redução da atividade bacteriana na cama como por se ligar quimicamente à amônia e impedir sua volatilização (OLIVEIRA; GODOI, 2010).

\subsection{Tratamento com aplicação de acidificantes na cama de frango}

$\mathrm{O}$ uso de produtos acidificantes tem como objetivo reduzir o pH da cama até níveis que gerem um ambiente pouco favorável à multiplicação de patógenos humanos associados às aves, especialmente, Campylobacter e Salmonella (LINE; BAILEY, 2006). De acordo com Silva (2011), o meio mais propicio para a multiplicação desses microorgansimos indesejáveis se encontram entre 6 e 9. Associado a isso, a utilização de acidificantes na cama de frango vem sendo utilizado não só na redução do $\mathrm{pH}$, como também na redução da volatilização da amônia (MEDEIROS et al., 2008).

Os efeitos da redução na volatilização de amônia estão relacionados com o decréscimo do $\mathrm{pH}$ que, com o aumento da concentração de íons $\mathrm{H}+$, favorece a formação de amônio (NH4 +) (PROCHNOW et al., 1995).

Os principais produtos com propriedades acidificantes são o bissulfato de sódio (POPE; CHERRY, 2000; LINE; BAILEY, 2006), sulfato de alumínio, superfosfato simples (OLIVEIRA et al., 2004), ácido sulfúrico (VICENTE et al., 2007) e o lignossulfato de sódio com ácidos fórmico e propiônico (GARRIDO et al., 2004).

$\mathrm{O}$ sulfato de alumínio reduz o $\mathrm{pH}$ da cama e Burgess et al. (1998) em seu estudo, observaram que a adição desse produto na proporção de $10 \%$ do peso da cama provoca queda no $\mathrm{pH}$ de 7,47 para 4,43 em cama composta por casca de arroz. Oliveira et al. (2004) concluíram que o sulfato de alumínio reduziu significativamente o $\mathrm{pH}$ da cama ao final de 42 dias de criação em todos os lotes testados.

Em relação à contagem média de bactérias mesófilas totais durante os 42 dias de alojamento, a cama tratada com produto natural a base de sulfato de cálcio e filossilicato expandido para higienização de camas de frango, perus, matrizes, avós e poedeiras apresentaram contagens menores em todas as granjas testadas conforme Werle et al. (2010). Pope; Cherry (2000) recomendam o uso de compostos acidificantes, como o sulfato de hidrogênio sódico e o sulfato de alumínio. Estes acidificantes são aplicados comumente à razão de 35 a 50 kg/ $100 \mathrm{~m}^{2}$ no dia anterior à recepção os pintinhos e geralmente apenas na área de pinteiro. Porém, segundo os autores, o efeito dos acidificantes não é maior do que 2 ou 3 semanas.

Deste modo, a ação dos acidificantes está em potencializar a diminuição do impacto negativo da cama principalmente nas duas primeiras semanas de vida da ave, sendo esta considerada as mais críticas. Segundo Butcher; Nilipour (2002), afirmam que erros cometidos nessa fase não poderão ser corrigidos, afetando assim o desempenho final das aves. Isso se deve, segundo Abreu (1999), por ser os primeiros 21 dias marcados pelo rápido desenvolvimento da ave e também por mudanças fisiológicas importantes, tais como: desenvolvimento do sistema termorregulador, início do desenvolvimento de imunocompetência, além do desenvolvimento de músculos, sistema ósseo e gordura. Portanto, o comprometimento dessa fase de desenvolvimento afeta negativamente o desempenho final do lote.

\section{CONCLUSÕES}

A qualidade da cama de frango é essencial para a boa condição sanitária do lote, pois é sobre esse material (cama) que ela passará a maior parte da sua vida, e vista vários lotes consecutivos também passarão por esse material, dessa forma a aplicação de algum método utilizado como tratamento se torna fundamental.

Vários tratamentos com condicionadores químicos para a cama são propostos pela literatura a fim de manter sua qualidade e assim promover um ambiente favorável para o bom desempenho das aves, com isso, o método da acidificação da cama vem se mostrando eficaz para a redução do $\mathrm{pH}$ e consequentemente, diminuição da volatilização da amônia, desencadeando assim, outros fatores qualitativos como a redução da carga microbiológica da cama, uma vez que esta está ligada diretamente com o $\mathrm{pH}$ da cama.

\section{REFERÊNCIAS}

ABREU, V. M. N. Manejo inicial e seus reflexos no desempenho do frango. Avicultura Industrial, p. 25-38, 1999.

ABPA_ASSOCIAÇÃO BRASILEIRA DE PROTEÍNA ANIMAL. Relatório Anual das Atividades de 2014. 2015. Disponível em http://www.abpa-org.br.Acesso em 27 julho de 2015

AVISITE. Noticías, Brasil: segundo maior produtor mundial de carne de frango. 2016. Disponível em: $<$ http://avisite.com.br/noticias/index.php?codnoticia $=165$ 3>. Acesso em: 15 de janeiro de 2016.

ALMEIDA, M. A. C. Fatores que afetam a umidade da cama. Avicultura Industrial, 76:16-18, 1986.

AVILA, V. S.; OLIVEIRA, U. de; FIGUEIREDO, E. A. P. de; COSTA, C. A. F.; ABREU, V. M. N.; ROSA, P. S. 
Avaliação de materiais alternativos em substituição à maravalha como cama de aviário. Revista Brasileira de Zootecnia, Viçosa, v. 37, n. 2, p. 273-277, 2008. DOI: http://dx.doi.org/10.1590/S1516-35982008000200013

AVILA, V. S. de; JAENISCH, F. R. F.; PIENIZ, L. C.; LEDUR, M. C.; ALBINO, L. F. T.; OLIVEIRA, P. A. V. de. Produção e manejo de frangos de corte. Concórdia: Embrapa Suínos e Aves-CNPSA, 1992. 43 p. (Documentos, 28)

BERALDO, M. C. Qualidade microbiológica de frango comercializado na cidade de Jaboticabal, São Paulo. Investigação, Franca, v. 13, n. 2, p. 24-28, 2013.

BERGEY, D. H; HOLT, J. G. Manual of Determinative Bacteriology. 9. ed. Baltimore: Williams \& Wilkins, 1994. $787 \mathrm{p}$.

BOSHOUWERS, F. M. G.; DAVELAAR, F. G.; LANDMAN, W. J. M.; NICAISE, E.; VAN DEN BOS, J. Vertical temperature profiles at bird level in broiler houses. British Poultry Science, v. 37, n. 1, p. 55-62, 1996. DOI: https://dx.doi.org/10.1080/00071669608417836

BURGESS, R. P.; CAREY, J. B.; SHAFER, D. J. The impact $\mathrm{f}$ ph on nitrogen retention in laboratory analysis of broiler litter. Poultry Science, v. 77, n. 12, p. 1620-1622, 1998. DOI: https://dx.doi.org/10.1093/ps/77.11.1620

BUTCHER, G. D.; NILIPOUR, A. H. Broiler management The first 24 hours. Gainesville: University of Florida Institute of Food and Agricultural Sciences, 2002. 4 p.

CARLILE, F. S. Ammonia in poultry houses: a literature review. World Poultry Science Journal, v. 40, n. 22, p. 99-113, 1984.

DAÍ PRÁ, M. A.; ROLL, V. F. B. Cama de frangos de corte Materiais reutilização e destino. In: Seminario Internacional de Manejo y Sistemas Operativos en Pollo de Engorde, 2014, Bogotá. Anais... Bogotá: AMEVEA, 2014.

DAÍ PRÁ, M. A.; CORREA, E. K.; ROLL, V. F. B.; XAVIER, G. X.; LOPES, D. C. N.; LOURENCO, F. F.; ZANUSSO, J. T.; ROLL, A. P. Quicklime reduces salmonella and clostridium sp counts in used broiler litter. In: European Poultry Conference, 13, 2010, Tours. Anais... Tours, 2010.

DAÍ PRÁ, M. A.; CORREA, E. K.; ROLL, V. F. B.; XAVIER, G. X.; LOPES, D. C. N.; LOURENCO, F. F.; ZANUSSO, J. T.; ROLL, A. P. Uso de cal virgem para o controle de Salmonella spp. e Clostridium spp em camas de aviário. Ciencia Rural, Santa Maria, v. 39, n. 4, p. 1189-1194, 2009.

DAO, T. H.; ZHANG, H. Rapid composition and source screening of heterogeneous poultry litter by x-ray fluorescence spectrometry. Annals of Environmental Science, v. 1, p. 69-79, 2007.

FERREIRA, J. C. Remoção de Amônia Gerada em Granjas Avícolas e sua Utilização em Células à Combustível e uso como Fertilizante. 2010. Tese (Doutorado) - Instituto de Pesquisas Energéticas Nucleares, Universidade de São Paulo, São Paulo, 2010.

FIORENTIN, L. Reutilização da cama na criação de frangos e as implicações de ordem bacteriológica na saúde humana e animal. Concórdia: Embrapa Suínos e Aves, 2005. 243 p. (Documentos, 94).

FRANCO, B. D. G. M. Microbiologia dos alimentos. São Paulo: Editora Atheneu, 1996. 182 p.

FREITAS, L. W.; GARCIA, R. G.; NÄÄS, I. de A.; CALDARA, F. R.; LIMA, N. D. da S. Volatilização de amônia em diferentes tipos de cama de frango. Revista Brasileira de Engenharia de Biossistemas, Tupã, v. 5, n. 3 , p. 142-151, 2011. DOI: http://dx.doi.org/10.18011/bioeng2011v5n3p142-151

FUKAYAMA, E. H.; LUCAS, J. J.; AIRES, A. M.; MIRANDA, A. P.; MACHADO, C. R. Avaliação da produção de camas reutilizadas de frangos de corte de quatro lotes. In: Simpósio Internacional sobre Gerenciamento de Resíduos de Animais Ordenamento Territorial das Produções Animais e Políticas Públicas Relacionadas ao Gerenciamento dos Resíduos de Animais, 1., 2009. Anais... Florianópolis, 2009. p. 583-588.

GRIMES, J. L. Alternatives litter materials for growing poultry. North Carolina Poultry Industry Newsltter, v. 1, n. 11, p. 1-4, 2004.

GARRIDO, M. N.; SKJERVHEIM, M.; OPPEGAARD, H.; SORUM, H. Acidified litter benefits the intestinal flora balance of broiler chickens. Applied and Environmental Microbiology, v. 70, n. 9, p. 5208-5213, 2004. DOI: https://dx.doi.org/10.1128/AEM.70.9.5208-5213.2004

GLOBALGAP. Pontos de controle e critérios de cumprimento: garantia integrada da fazenda - aves. Cologne: GLOBALGAP, 2007. 22 p.

GONZÁLES, E.; SALDANHA, E. S. P. B. Os primeiros dias de vida do frango e a produtividade futura. In: CONGRESSO BRASILEIRO DE ZOOTECNIA, 2001, Goiânia. Anais... Goiânia: AZEG/ABZ, 2001. p. 312-313.

HERNANDES, R.; CAZETTA, J. O. Método Simples e acessível para determinar amônia liberada pela cama. Revista Brasileira de Zootecnia, Viçosa, v. 30, n. 3, p. 824-829, 2001. DOI: http://dx.doi.org/10.1590/S151635982001000300030

HERNANDES, R.; CAZETTA, J. O.; MORAES, V. M. B. Frações Nitrogenadas, Glicídicas e Amônia Liberada pela Cama de Frangos de Corte em Diferentes Densidades e Tempos de Confinamento. Revista Brasileira de Zootecnia, Viçosa, v. 31, n. 4, p. 1795-1802, 2002. DOI: http://dx.doi.org/10.1590/S1516-35982002000700023

IVANOV, I. E. Treatment of broiler litter with organic acids. Research in Veterinary Science, v. 70, n. 2, p. 169-173, 2001. DOI: https://dx.doi.org/10.1053/rvsc.2001.0454

JORGE, M. A.; MOUCHREK, E.; CARNEIRO, M. I. F.; RESENDE, J. S.; MARTINS, N. R. Coliformes, umidade e produção de amônia em cinco tipos de cama de frango. Anais da Semana Avícola, 95., 1995, São Paulo. Anais... São Paulo: FACTA, 1995.

JONES, E. K. M.; WATHES, C. M.; WEBSTER, A. J. F. Avoidance of atmospheric ammonia by domestic fowl and the effect of early experience. Applied Animal Behaviour Science, Londres, v. 90, n. 3-4, p. 293-308, 2005. DOI: https://dx.doi.org/10.1016/j.applanim.2004.08.009

JEFFREY, J. S. Inactivation of bacteria in stacked poultry litter. Davis: University ocalifornia, 2001. 8 p.

KWAK, W. S.; HUH, J. W.; MCCASKEY, T. A. Effect of processing time on enteric bacteria survival and on temperature and chemical composition of broiler poultry litter processed by two methods. Bioresource Technology, Essex, v. 96, n. 14, p. 1529-1536, 2005. DOI: https://dx.doi.org/10.1016/j.biortech.2004.12.018

LANA, G. R. Q. Avicultura. Recife: Editora Rural Ltda., 2000. 268 p. 
LAVERGNE, T. K.; STEPHENS, M. F.; SCHELLINGER, D.; CARNEY, W. A. In-house pasteurization of broiler litter. Louisiana Cooperative Extension, 2006. 16 p.

LINE, J. E.; BAILEY, J. S. Effect of on-farm litter acidification treatments on Campylobacter and Salmonella populations in commercial broiler houses in Northeast Georgia. Poultry Science, Champaign, v. 85, n. 9, p. 15291534, 2006. DOI: https://dx.doi.org/10.1093/ps/85.9.1529

LUCCA, W.; CECCHIN, R.; TIMPOLA, E.; GRADIN, J.; LUCCA, M. S. Efeito de diferentes tratamentos químicos em cama para aves de corte. Revista Agroambiental, Pouso Alegre, v. 4, n. 1, p. 25-31, 2012. DOI: http://dx.doi.org/10.18406/2316-1817v4n12012371

MEDEIROS, R. A adição de diferentes produtos químicos e o efeito da umidade na volatilização de amônia em cama de frango. Ciência Rural, v. 38, n. 8, p. 2321-2326, 2008.

MIRAGLIOTTA, M. Y. Avaliação dos níveis de amônia em dois sistemas de produção de frangos de corte com ventilação e densidade diferenciados. 2000. 122f. Dissertação (Mestrado) - Universidade Estadual de Campinas, 2000.

NASCIMENTO, G. R.; NÄÄS, I. A.; PEREIRA, D. F.; BARACHO, M. S.; GARCIA, R. Assessment of broilers surface temperature variation when exposed to different air temperature. Revista Brasileira de Ciência Avícola, Campinas, v. 13, n. 4, p. 259-263, 2011. DOI: http://dx.doi.org/10.1590/S1516-635X2011000400007

OLIVEIRA, R. F. M; DONZELE, J. L; ABREU, M. L. T; FERREIRA, R. A; VAZ, R. G. M. V; CELLA, P. S. Efeitos da temperatura e umidade relativa sobre o desempenho e o rendimento de cortes nobres de frangos de corte de 1 a 49 dias de idade. Revista Brasileira de Zootecnia, Viçosa, v. 35, n. 3, p. 797- 803, 2006.

OLIVEIRA, M. C.; GODOI, C. R. Tratamento da cama de frango sobre o desempenho das aves equalidade da carcaça e da cama. Revisão de literatura. PUBVET, Londrina, v. 4, n. 7, p. 752-758, 2010.

OLIVEIRA, M. C.; FERREIRA, H. A.; CANCHERINI, L. C. Efeito de condicionadores químicos sobre a qualidade da cama de frango. Arquivo Brasileiro de Medicina Veterinária e Zootecnia, Belo Horizonte, v. 56, n. 4, p. 536-541, 2004. DOI: http://dx.doi.org/10.1590/S010209352004000400016

OLIVEIRA, M. C.; ALMEIDA, C. V; ANDRADE, D. O; RODRIGUES, S. M. M. Teor de matéria seca, $\mathrm{pH}$ e amônia volatilizada da cama de frango tratada ou não com diferentes aditivos. Revista Brasileira de Zootecnia. V. 32, n. 4, p. 951- 954, 2003

POPE, M. J.; CHERRY, T. E. An evaluation of the presence of pathogens on broiler raised on poultry litter treatment treated litter. Poultry Science, v. 79, n. 9, p. 1351-1355, 2000. DOI: https://dx.doi.org/10.1093/ps/79.9.1351

PROCHNOW, L. I. Controle das perdas de amônia durante a compostagem de estercos com adição de fosfogesso e superfosfato simples. Scientia Agrícola, Piracicaba, v. 52, n. $2, \quad$ p. $346-349, \quad 1995 . \quad$ DOI: http://dx.doi.org/10.1590/S0103-90161995000200024

QIU, G.; GUO, M. Quality of poultry litter-derived granular activated carbon. Bioresource Technology, Essex, v. 101, n. $1, \quad$ p. 379-386, 2010. DOI: https://dx.doi.org/10.1016/j.biortech.2009.07.050

RANDALL, D.; BURGGREN, W.; FRENCH, K.; FERNALD, R. Equilíbrio osmótico e iônico. In: Fisiologia animal: mecanismos e adaptações. 4.ed. Rio de Janeiro: Guanabara-Koogan, 2000. p.531-581.

REHBEGER, T. C. Controlling litter microorganisms. EDigest, v. 2, n. 6, p. 1-6, 2002.

RESENDE, F. M. S. Análise Físico-Químicas e Virucidas da Fermentação Com Cobertura e Sem Amontoamento da Cama de Aves. 2010. 49f. Dissertação (Mestrado em Medicina Veterinária) - Escola de Veterinária, Universidade Federal de Minas Gerais, Belo Horizonte, 2010.

ROLL, V. F. B.; DAÍ PRÁ, M. A.; ROLL, A. P. Research in broiler litter reused for up to 14 consecutive flocks. Poultry Science, Champaign, v. 90, n. 10, p. 2257-2262, 2011. DOI: https://dx.doi.org/10.3382/ps.2011-01583

SANTOS, M. J. B.; SAMAY, A. M. A. T.; DEMOSTHENES. A. T. Manejo e tratamento de cama durante a criação de aves. Revista Nutrime, v. 09, n. 3, p. 1801-1815, 2012.

SANTOS, E. C.; COTTA, J. T. de B.; MUNIZ, J. A.; FONSECA, R. A. da; TORRES, D. M. Avaliação de alguns materiais usados como cama sobre o desempenho de frangos de corte. Ciencia e Agrotecnologia, Lavras, v. 14, n. 4, p. 1024-1030, 2000.

SILVA, G.; DUTRA, P. R. D.; CADIMA, I. M. Higiene na indústria de alimento. Recife: EDUFRPE, 2010. 132 p.

SILVA, V.S. Estratégias para reutilização da cama de aviário. Conferencia Facta, de ciência e tecnologia avícolas, Santos, SP, 2011.

SOUZA, J. C. P. V. B. Embrapa participará de definição de boas práticas de reutilização da cama do aviário. 2005. Disponível em: < https://www.embrapa.br/busca-denoticias/-/noticia/17981212/embrapa-participara-dedefinicao-de-boas-praticas-de-reutilizacao-da-cama-doaviario>. Acesso em 27 julho de 2015.

TERZICH, M. A. Amônia dos galpões avícolas e o pH da cama. In: Conferência Afinco de Ciência e Tecnologia Avícolas, 1997, São Paulo. Anais... São Paulo: Associação Brasileira dos Produtores de pintos de Corte, 1997. p.141146.

TIQUIA, S. M.; TAM, N. F. Y. Fate of nitrogen during composting of chicken litter. Environmental Pollution, Oxford, v. 110, n. 3, p. 535-541, 2000. DOI: https://dx.doi.org/10.1016/S0269-7491(99)00319-X

TRABULSI, L. R.; ALTERTHUM, F.; GOMPERTZ, O. F.; CANDEIAS, J. A. N. Microbiologia. 3. ed. São Paulo: Atheneu, 1999. 920 p.

TRABULSI, L. R.; CAMPOS, L. C. Generalidades sobre enterobactérias. In: TRABULSI, L. R.; ALTERTHUM, F.; GOMPERTZ, O. F.; CANDEIAS, J. A. N. Microbiologia. 3 ed. São Paulo: Atheneu, 2002. p. 207-213.

VICENTE, J. L.; HIGGINS. S. E..; HARGIS, B.M. Effect of Poultry Guard litter amendment on horizontal transmission of Salmonella enteritidis in broiler chicks. International Journal of Poultry Science, v. 6, n. 5, p. 314-317, 2007.

WERLE, G.; LOVATO, M.; WILSMANN, C. G.; GAZONI, F. G.; CHAVES, B. W.; BRUSTOLIN, J. M.; Avaliação microbiológica da cama de frangos de corte tratada com Ecodryaves. Jornada Acadêmica Integrada. 25., 2010, Santa Maria. Anais... Santa Maria: UFSM, 2010.

ZANATTA, A. R. Análise do Controle de Amônia em Aviários. Universidade do Extremo Sul Catarinense. 2007. 62f. Monografia (Trabalho de Conclusão de Curso) - Universidade do Extremo Sul Catarinense, Criciúma, 2007. 